\title{
Strategies of risk communication: \\ Observations from two participatory experiments
}

\author{
ORTWIN RENN
}

Risk analysis has gained popularity as a scientific tool to determine the magnitude and probability of an adverse effect associated with a technology or human activity. The use of risk analyses for policy purposes requires efforts to communicate risk information to decision makers, stakeholders, and the general public. Many decision makers and risk analysts must face the inability of most people to understand, assimilate, and process probabilistic risk information. Common sense usually relies on deterministic thinking: a technology is either safe or unsafe, a medical treatment effective or useless, a pollutant perilous or innocuous (Ruckelshaus 1982).

The notion of probability involves various degrees of safety, healthiness, and effectiveness based on observations on the past performance of the risk source or its components. Deterministic reasoning cannot provide a yardstick for comparing risk sources and weighing their potential impacts. Therefore, one goal of risk communication is to convey the basic concept and rationale of risk assessment to a layperson audience so that people understand and comprehend the results and implications.

Linked to this goal is the need for risk managers to communicate the findings of risk studies for initiating individual actions to enhance personal protection, to alert people about hazardous situations, to foster changes in lifestyle, and to inform residents about local emergency guidelines (Covello, Slovic, and von Winterfeldt 1986). The objective is increased individual safety or at least a consciousness about the hazards involved in many occupational and leisure activities.

A third major goal of risk communication is to introduce risk analysis as a suitable tool for forming compromises in negotiations with affected parties. The process of designing and promulgating environmental policies requires the incorporation of stake-holder groups with divergent interests. Deterministic thinking essentially encompasses merely yes-no decisions that render one party the absolute winner and the other the loser. A quantitative risk analysis provides ample room for all parties to make their own case. One group may require substantial improvements in the safety system, thus decreasing the 457

R.E. Kasperson and P.J.M. Stallen (eds.), Communicating Risks to the Public, 457-481. (C) 1991 Kluwer Academic Publishers. Printed in the Netherlands. 
assessed probabilities or magnitudes of the risk but without opting for the elimination of the risk source (and thereby drawing fierce opposition by the proponent of the facility). Different grades of safety or health allow for collective bargaining and negotiations, both essential processes in the licensing and regulatory procedure (Renn 1985).

In addition, risk analysts and managers may use risk communication as a means to learn from the public by listening to the concerns of local residents, public interest groups, and informed citizens. Public input is necessary to include risk-related properties other than magnitude and probability. Issues such as equity of risk bearing, catastrophic versus routine occurrence of losses, the circumstances of risk, and the ability of institutions to monitor and control hazardous facilities are excluded from formal risk analysis and hence not reflected by any risk calculation. Potential victims have a much better sense of risky situations and can communicate their concerns and observations to risk managers or regulators. Both information inputs - the scientific assessment of the probabilities as well as the public perception of the circumstances of the risk-bearing situation - are necessary elements of a rational decision-making process. Risk communication, in both directions, is crucial to society's ability to cope with risk (Kasperson 1986).

But how should risk communication be designed to meet the functions of enlightenment (orientation knowledge), enhancement of personal protection, conflict resolution, and policy input via two-way communication? Are instruments available that are attractive for citizens and at the same time effective for conveying the basic ideas of risk analysis?

This chapter describes and analyzes the experiences with "Planning Cells", a novel instrument of public participation designed to convey scientific information to groups of laypersons and to elicit their preferences with respect to policy options. All functions of risk communication were involved, but most emphasis is placed on the two-way communication process. Most of the findings presented here are derived from a large-scale experiment in the Federal Republic of Germany; the purpose of which was to use planning cells as a means to assess and evaluate different energy scenarios for the Federal Republic of Germany (Renn 1986; Renn et al. 1984; Renn et al. 1985).

A similar effort was undertaken in 1988 for the New Jersey Department of Environmental Protection. This study applied the method of planning cells for eliciting citizen's preferences for regulatory options with respect to land application of sludge. Since the project was still in progress at the time of writing this chapter, this chapter focuses on the results of the West-German experiment. At the end, however, it addresses also the results of the New Jersey project to discuss some of the impressions gained from applying the use of planning cells in the U.S. context. 


\section{Design and methodology}

In August 1982, the German Ministry of Research and Technology initiated a large research project to investigate the preferences of the German population with respect to four energy policy options developed by a parliamentary commission in 1979. The Government was interested in eliciting reliable information on which energy scenario was most appealing to the population and on what basis citizens would evaluate the policy options laid out in each scenario. A research team directed by the author conducted a three-year study to collect data on public preferences and to analyze the motivations and underlying reasons for the judgmental process of evaluating the predefined energy scenarios. The study comprised three steps:

- Values and criteria to assess and evaluate energy options were identified by interviewing representatives of ten major stake-holder groups in West Germany (Keeney, Renn, and von Winterfeldt 1987).

- Around 30 energy experts were asked to give their best scientific estimates for the performance of each energy scenario on each of the revealed criteria (Renn 1984).

- The resulting profiles of each energy scenario were conveyed to randomly selected citizens for evaluation and comment (Renn 1986).

For the purpose of this analysis, only the third step is of significance. Asking a sample of the public directly what they think about the four scenarios would have been of limited value. One of the main shortcomings of public opinion polls for determining public preferences and policy evaluations is the inability of most respondents to assess the likely consequences of their own judgments. Since many people associate quite a few false assumptions and incorrect impacts with different energy systems and others do not know how to react because they are confused by the ongoing scientific debate, it was necessary to educate our sample of respondents prior to recording their judgment.

Informing people about the likely consequences of their preference in advance involves the danger of manipulation, in particular of triggering biased responses according to the information presented and the basic attitudes of the instructing experts. To avoid biased responses, we invited experts with different attitudes, in particular about nuclear energy, to review our basic material and to design the curriculum together with us. The material was divided into three categories: basic factual knowledge that all experts could agree on, interpretation of facts (for example, what does an emission of $x$ amount of $Y$ mean in terms of public health?), where we tried to include the most significant viewpoints, and evaluation of facts (for example, will civil liberties be endangered by nuclear energy?) that we reported in brief essays. The consulted 
experts as well as the participants assured us that they did not detect any bias in the information and that they thought all relevant positions well represented. In addition to the written material and lecture outlines, we invited experts with different points of view to participate in a hearing before the citizen panels. The audience also viewed videotapes of the main arguments.

The idea was to engage citizens in a procedure similar to a jury trial. Formal hearings, lectures, videofilms, inspection tours, written information, and mutual discussions provided the informational basis for reaching a well-balanced judgment on the options available. The specific method of using such citizen's panels for policy making was developed by P.C. Dienel $(1980,1987)$ at the University of Wuppertal and successfully applied in local and regional planning problems. The study on national energy problems was the first application of this method for designing national policies.

Dienel assigned the term "planning cells" to the citizen panels. A planning cell consists of a group of citizens who are selected by a random process and are given paid leave from their workday obligations for a limited period of time in order to work out solutions for given, soluble planning problems with the assistance of advisors on procedure.

A small group (usually 25 people) is assembled to work on a predefined task taking advantage of group dynamics and the absence of traditional social control mechanisms (such as status and hierarchy). Since the participants are selected by a random procedure, they are not necessarily individually affected by the planning problems to be solved. To encourage participation and personal commitment, they are assigned the socially highly esteemed role of a "consultant" in the public planning process.

In our study we operated with 24 planning cells drawn from seven communities in different parts of West Germany. The planning cell meetings were held in public buildings for four consecutive days. Naturally not all persons who were asked to take part in the procedure were able to attend. Only 20 percent of all invited persons did participate, so that a true representation of the West German public was not accomplished. But a comparison of the basic demographics of our participants with the national average revealed that our sample was a good representation of the different age groups, income classes, and educational backgrounds. The only clear bias involved the distribution of professions. Hardly any self-employed person was able to sacrifice four days, whereas housewives, retired people, and public servants were slightly overrepresented. For purposes of this chapter on risk communication, this nonrepresentative sample composition is more of an advantage, since persons with no background in probabilistic risk assessment comprised the vast majority of our sample.

The objective of the study was to elicit preferences of our participants and to 
lead them to evaluate the different options by taking into account the best scientific estimates of the likely impacts of each option and their personal value judgments. The task for each participant was hence to rate each energy system according to the given criteria, to assign relative weights to each criterion, and to come up with a balanced recommendation as to which energy scenario should be implemented to meet future energy demands. Therefore, our data collection clearly focused on the weighting of criteria and the evaluation of energy options. But we also tested, at least indirectly, several concepts of communicating probabilistic information and were able to reconstruct some major pathways of how individuals assimilate and process risk-related information.

\section{The structure of risk communication in the planning cells}

More than a year of preparation was invested to design an appropriate agenda for the four days and to train the advisors and experts for their task of communicating the nature, benefits, and risks of different energy systems and scenarios. Since at that time similar projects combining education and participation in energy policy making were lacking or at least not completed (Sweden and the Netherlands have conducted citizens panel discussions on energy politics but had not published the results in 1982), the design of our information program relied upon existing studies on risk and technology. In addition, we conducted four pretests involving different curricula for the planning cell procedure.

A review of the literature led us to acknowledge the major difficulties of communicating risk-related information. In particular, psychometric and attitudinal studies prompted us to confront a series of problems:

- Inaccurate perception of the meaning of probabilities;

- Overconfidence in one's own ability to manage and control risky situations;

- Thirst and desire for scientific certainty and unanimity among experts;

- Tendency to underestimate natural and to overestimate technological (human made) risks

- Reluctance to make trade-offs between different types of risks or risk sources;

- Fear of unfamiliar, low-probability high-consequence risk sources

- Strong preoccupation with risk-related factors such as equity, voluntariness, and societal ability to manage and control risk source.

In addition to problems in the ability and willingness of the individual to understand and process risk-related information (see Chapter 5), we summa- 
rized the findings of risk perception studies on what matters to most people and what influences their judgment on the acceptability of a risk or a risk source. Basically we tried to incorporate the insights of risk perception studies into the design of our communication program. Table 19.1 summarizes the major highlights of risk perception studies, as encountered by our research team.

In particular, we were aware that most risk experts equate the term risk with average annual mortality whereas laypersons associate different meanings with the term risk depending on the context and incorporate several independent dimensions when evaluating the riskiness of an activity or event (as outlined in Table 19.1). Furthermore, laypersons tend to show less concern for statistically calculated victims (such as one out of a thousand) as opposed to identifiable individuals (My neighbor will die as a result of activity Y). Statistical losses seem only to matter if individuals can picture themselves or close relatives and friends as potential victims (Royal Society 1983). As a result of our review of the literature, we developed a set of guidelines, summarized in Table 19.2, for our experts and instructors.

The guidelines for risk communicators were reviewed by experts on risk communication. For the more specific question of how to frame our information process and what kind of channels and media we should utilize, we conducted a pretest with four planning cells, each consisting of 25 persons. The groups received the same substantial information, but in four different ways:

1. The first group was informed by a proponent and an opponent about each of the controversial energy systems. A panel discussion among the communicators and with the audience was scheduled after each individual expert had the chance to present his or her arguments.

2. The second group received from a "neutral" expert information on the technical characteristics of the energy systems. A panel discussion with pro and con experts followed.

3. The third group was also informed by a neutral expert prior to a hearing in which the audience interviewed experts, representatives of interest groups, and politicians about their arguments concerning the different policy options and energy systems.

4. The fourth group was again given technical information first. Instead of a panel discussion, however, the audience viewed videotapes containing statements of leading pro and con experts.

The test of our information strategies does not satisfy the requirements for an experimental design. First, a real control group is missing, and, second, not all combinations of presenting the information were included. But time and money constraints precluded the pretests exceeding more than four experi- 
Table 19.1. Summary of risk perception studies.

\section{Perception is a function of: 1}

- intuitive heuristics, such as availability, anchoring effect, overconfidence, and others

- perceived average losses over time

- situational characteristics of the risk or the consequences of the risk event

- associations with the risk source

- credibility and trust in risk-handling institutions and agencies

- media coverage (social amplification of risk-related information)

- judgment of others (reference groups)

- personal experiences with risk (familiarity)

Perception is influenced by: ${ }^{2}$

- voluntariness

- controllability

- catastrophic potential

- delay of consequences

- tendency to kill rather than to injure

- perceived threat to future generations

- equal exposure to risk

- equal risk-benefit distribution

- familiarity with risk

- perception of benefits

- exclusiveness of benefits

\section{'Sources:}

Borcherding, K., B. Rohrmann and T. Eppel. 1986. A psychological study on the cognitive structure of risk evaluations. In: B. Brehmer, H. Jungermann, P. Lourens and G. Sevon (eds), New directions in research on decision making. Amsterdam, The Netherlands: Elsevier Science and North Holland Publisher, pp. 245-262.

Kahneman, D. and A. Tversky. 1974. Judgement under uncertainty. Heuristics and biases. Science 185: 1124-1131.

Renn, O. 1983. Technology, risk und public perception. Angewandie Systemanalysel Applied Systems Analysis 4, No. 2: 50-65.

Slovic, P. 1987. Perception of risk, Science 236, No. 4799: 280-285.

\section{Sources:}

Covello, V.T. 1983. The perception of technological risks: a literature review. Technological Forecasting and Social Change 23: 285-297.

Jungermann, H. 1982. Zur Wahmehmung und Akzeptierung des Risikos von Großtechnologien. Psychologische Rundschau 23: 217-229.

Otway, H. 1980. Perception and acceptance of environmental risk. Zeitschrift für Umweltpolitik 2: 593-616.

Slovic, P., S. Lichtenstein and B. Fischhoff. 1982. Why study risk perception? Risk Analysis 2, No.2 (June): 83-93.

Vlek, C. and P.J. Stallen. 1981. Judging risks and benefits in the small and in the large. Organizational Behaviour and Human Performance 28: 235-271. 
mental groups. Thus we decided to use four different combinations of information strategies that we thought were most likely to fit well together. By collecting the evaluation for each segment of the communication program, however, we were able to judge the relative preference for each option.

Our respondents were asked to evaluate the communication effort on a semantic differential instrument dealing with different evaluative categories (e.g. objectivity, clarity, completeness, adequacy, and consistency). It should be noted that we did not test factual knowledge or comprehension of the material presented. Rather, we focused on the subjective impression of our respondents.

The results were astonishingly unambiguous. The rating for strategy 4 dominated clearly all other alternatives. With the exception of diversity of viewpoints and comprehensiveness, the combination of technical expertise and videofilm was perceived as superior in all other categories. Table 19.3 summarizes the major advantages of videotaping expert controversies.

Since our respondents missed the liveliness of a panel discussion and questioned the completeness of the information received, we combined strategies 3 and 4 and composed a three-step information sequence. First, a technical expert, prepared to present only material that in the previous expert ratings received unanimous agreement, lectured for approximately $\mathbf{3 0}$ minutes about

Table 19.2. Guidelines for risk communication.

- Specify your intentions and goals at the beginning of each presentation.

- Try to convey the basic rationale of risk analysis to your audience by referring to everyday experiences of probabilistic judgments. Good illustrations are consumer choices, the stock market, sweepstakes, or the weather forecast.

- Start always with the list of facts and models that all experts agree on in principle, then develop your own arguments and interpretations.

- Try to escape from role expectations by using a personal approach, and relate the risk to the experience of each participant

- Be cautious in quoting risk numbers or showing risk diagrams. Probabilities do not mean anything to most people unless the numbers are compared with the expected values of other risk sources. Comparisons of risk should be used to illustrate probabilities and not to document or justify acceptability. In addition, comparisons should be confined to equifunctional systems.

- Share the anxieties and inner conflicts of the audience and reveal your personal value conflicts when arguing for one or the other energy scenario.

- Emphasize that some of the crucial risk properties (such as voluntariness and personal control) refer to individual decision making, whereas risk sources relying on collective decision making usually do not encompass these possibilities. Functional equivalents, however, such as institutional control and open information policies, are available to compensate for the lack of personal control. 
the energy system or scenario in question. A question-and-answer period followed focusing on topics that needed additional clarification. After the lecture came a videotape repeating some of the technical aspects and showing two-minute statements for each category (safety/ health, environment, costs, economic impacts, social impacts, political implications, and international impacts) given by a representative of the opponent and proponent group. Questions for clarification were also handled by the present expert, but closely supervised by the group advisor to avoid any biases. In a third step, a hearing was conducted with members of the main political parties (including the Greens) where the participants of the planning cells could raise prepared and spontaneous questions. In addition, all participants received the results of our expert survey and the list of the values revealed in our interrogation of stakeholder groups. The participants were randomly assigned to small discussion and working groups of five to digest the material, discuss potential applications, and prepare questions for the politicians.

To avoid the danger of overtaxing or overcommitting our respondents, we implemented the full information sequence only for the two most controversial energy systems: nuclear and solar energy. For the four energy scenarios, which basically differed in their utilization rate of nuclear versus solar energy and conservation, videofilms were not prepared because most arguments were already covered in the films on the two controversial energy systems.

Table 19.3. Advantages of expert statements on videotapes.

- Each expert can thoroughly prepare his or her statement and tailor it to the needs of a layperson audience.

- For a videotape session, the most prominent adversaries are usually available whereas in real life discussions only local experts may have the time to participate.

- All experts can repeat recording their statements as often as they wish to. If the expert is satisfied with the final result, he or she has probably given his or her best to communicate the intended message.

- Each expert is given the same time allowance and thus was treated equally and fairly.

- The statements can be structured according to a prepared outline which is developed by or discussed with the citizen panels.

- Videotapes can be replayed several times so that difficult arguments can be viewed more than once.

- Videotapes lack the dynamics and liveliness of panel discussions, but the audience does not get lost as often as in live discussions. In addition, non-argument related aspects (such as the appeal of an expert and the rhetoric of the performance) play a less decisive role. 


\section{Results of the communication effort}

Indicators of success and failure: How well was the information on risks and benefits of different energy scenarios and systems perceived? In which way did we succeed in conveying the basic rationale of risk assessment? How did people incorporate risk judgments in their overall evaluation of energy options? Unfortunately, we cannot provide sufficient statistical evidence to respond to these questions. Since our objective was to elicit preferences and evaluations of energy systems, we did not specifically ask for opinions or ratings of the different information procedures and contents. Therefore, we had to rely on more indirect data sources and in some instances on personal impressions. We gained insights about the effectiveness and results of our communication effort from a variety of sources:

- We asked each respondent to make trade-offs between different risk sources and to design compensation strategies for those people who would be worse off if the respondent's preferred option were chosen. Risk-related data were given to perform this task. Without an understanding and an appreciation of the risk assessment method, this task was impossible to perform.

- Each respondent made risk-related assessments with respect to health and safety as well as environmental quality. From these data, one can infer the way probabilistic information was processed.

- Content analysis was used to investigate the major arguments brought forward by each participant to justify his or her final decision on which scenario should serve as the major guideline for national energy policy making. From these data, the percentage of risk related information was extracted.

- All advisors on procedure (two for each planning cell) as well as the student assistants (also two for each planning cell) had to fill out an evaluation form that elicited an assessment of the overt effects of each information sequence.

- The author participated in six of the 24 planning cells and gained an impressionistic view as to which kind of information was readily accepted and digested and which was rejected or ignored. Since most planning cell runs were videotaped, these impressions could be substantiated by watching similar information sequences.

The results fall into two basic categories: the perception of risk-related information, and the processing of this information to articulate and justify one's own judgment. 
Perception of risk-related information: The rationale of risk assessment was understood and also appreciated as a viable tool of decision making. The need to assign trade-offs to conflicting values and to consider differences in probabilities as one yardstick for evaluating the seriousness of consequences was reflected in the numerical responses of the participants for assessing and weighting health, safety, and environmental impacts. None of the respondents refused to assign trade-offs, even between adverse health effects and costs, nor were low-probability, high-consequence events always seen as inferior to more probable, but less severe incidents. This finding contradicts the theoretical implication of some cultural analysts of risk perception who claim that people attached to the environmental movement are not willing to accept the rationale of making trade-offs between environmental quality and other categories (e.g., Douglas and Wildavsky 1982). Our results seem to indicate, at least for panels of randomly selected citizens, that the rejection of trade-offs is more a question of strategic bargaining than a matter of personal conviction.

Also, our respondents, facing fellow citizens with divergent viewpoints, accepted the legitimacy of each value category and thus conceded that decisions should not be made on the basis of the criteria that each individual respondent deemed important. This, of course, may be attributed to the lack of openly documented commitments that may prevent members of stakeholder groups from accepting in public the legitimacy of the values of other groups. Uncommitted citizens do not "lose face" when they tolerate and even appreciate viewpoints contrary to their own. Furthermore, these citizens felt the need to incorporate values of other citizens into the decision making process even if these values were in opposition to their own values.

One of the reasons that most participants could handle difficult trade-off problems and deal with probabilities was their familiarity with budget constraints in their everyday lives (Fischhoff, Svenson, and Slovic 1986). Most participants had first hand experience with budget constraints and hence for making trade-offs between costs and safety. Again, the common misconception that most people are unwilling or unable to accept the premise of commensurability of money and health effects should be reconsidered in the light of our experiences. Many respondents reported on their own constraints when trading gains or losses of safety against prices of goods. Buying a car equipped with effective, but expensive safety features versus purchasing an inexpensive, but less safe vehicle, for example, constituted a common dilemma that many respondents had faced in the past. The variance of trade-offs actually assigned between the two categories was very high, thus causing considerable debate and conflict among the participants. However, not a single person refused to make this trade-off, or even expressed doubts about the value of this proce- 
dure. The high compliance rate was certainly facilitated by the group interaction and the assigned roles of the participants as public consultants. Yet it appears that, within an intensive and well-structured communication process, the idea of relative safety can be successfully conveyed.

Although taken into account, probabilities were more difficult to communicate, particularly for the purpose of evaluating outcomes. Most participants had an abstract idea of probabilities, but the concrete meaning and instrumental application of probability concepts were difficult to impart. On the one hand, risk sources characterized by different probabilities of a specific adverse effect (e.g. loss of life) were indeed assessed and evaluated differently, so that probabilities were certainly considered. On the other hand, the catastrophic potential of a risk source dominated clearly the overall estimation of riskiness.

Nuclear energy received an overall negative evaluation for the corresponding health impacts, even though it scored positively in almost all subcategories constituting the health risk category (i.e.occupational health hazards, average fatalities, morbidity, nonfatal health effects). Negative assessments were assigned only to the subcategory catastrophic potential. In the process of amalgamating the five subcategories of health risk into one dimension, the positive average fatality scores were all overcompensated by the perception of the catastrophic potential. This is the only logical explanation for the composite negative judgment. The mean over the five subcategories is significantly lower than the value assigned to the composite effect. Using a simple linear regression analysis, the weight for the catastrophic potential must be 0.7 at least in order to compensate the scores of the other four subcategories. This result is not surprising, at least in principle, since risk perception studies have demonstrated the importance of the catastrophic potential for individual perception of riskiness. But the magnitude of this effect was unexpectedly high.

More recent research on risk perception attributes the high sensitivity to catastrophic potential to the public concern for society's ability to cope with large accidents and its capability to control potentially dangerous technologies. It also suggests that the expected or perceived number of victims in a single accident is only slightly correlated with perceived riskiness of such an event (e.g., Renn 1983). Our results seem to underline this hypothesis since the more numerical subcategories of average losses were perceived as much less important than the composite effect of one catastrophe.

Furthermore, technologies with high catastrophic potential were perceived as more inequitable than technologies with more frequent, but less dramatic effects. Although experts have demonstrated that low-probability, high-consequence risks are usually more equitable than high-frequency, low-consequence risks (Keeney 1980), most participants believed the contrary. They were convinced that a rare event would more likely affect the "innocent" 
bystanders or even future generations, whereas the beneficiaries of such technologies would probably "get away with it".

The understanding of probability was clearly analogous to perceived risks taking in economic ventures. The perception here is that managers who are risking the fate of the whole company for making profits may benefit tremendously in the short run, but will ruin the company in the long run. The lower the probability of the financial ruin, the more likely it is that the immediate beneficiaries will not experience this fate but their successors will. Since enough anecdotal evidence exists for such delayed costs of short-term profitseeking, it was almost impossible to convey the mathematical concept of probability independence with regard to time and previous outcomes. Overwhelmingly, people were convinced that the probability of a catastrophe would increase with every year the catastrophe did not occur. Under this premise, future generations are inevitably more at risk than the present generations even though they may not enjoy the benefits. Simply stated, after three occurrences of tails in tossing coins, most people believe that it is more probable to obtain heads in a fourth trial than tails.

One attempt to make probabilities more comprehensible to the participants was the use of risk comparisons. By putting risks into perspective, the objective of the communication process, as reviewed in Chapter 5, was to compare the risks of known and familiar risk sources to new and controversial risks. Such comparisons were perceived in an ambivalent manner. When experts focused on the consequence of a risk as the common denominator for the comparison, such as the probability of getting lung cancer from smoking versus living next to a coal-fired power station, the panel reacted with incomprehension or even anger. The panels accepted only comparisons among risks of equifunctional systems, such as power generating facilities. Not even then did the average score of the individual risk assessment reflect the numerical distance between the scientific probability estimates.

In essence, our approach succeeded in conveying the underlying rationale of risk analysis and in explaining the meaning of probabilities and models for determining adverse effects. The participants also obtained an understanding of the problems of regulatory agencies, particularly seeking an adequate balance between avoiding negative health effects and fostering economic prosperity. Nevertheless, the average probability estimates had only a minor impact on the rating of the seriousness of health and environmental effects. The average expected fatality rate was clearly understood and also appreciated as a means of classifying risk, but the catastrophic potential was perceived as the major and dominant contributor to the perceived seriousness of a risk. This result has some interesting implications: 
1. The majority of our sample does not share the underlying value judgment in technical risk analysis to give equal weight to probability and magnitude and not to differentiate between a low-probability, high-consequence and highprobability, low-consequence risk having the same expected value.

Although our sample is not a true representation of the West German population and the scope of risk sources was restricted to energy systems, the unanimity of rejecting average annual fatalities as a yardstick to evaluate risk suggests a clear divergence between expert and layperson judgments. Expected values were neither ignored nor misunderstood; they were simply assigned a minor importance in evaluating risk. This conclusion has been confirmed by almost all survey results on risk perception (see references in Table 19.2).

2. The divergence between risk experts and laypersons is not caused by public ignorance or misunderstanding of the probability concept but appears to be rooted in different underlying value judgments.

Whereas experts rate the seriousness of risks as a function of the number of victims per time unit, the majority of laypersons focuses on the worst conceivable incident and the dispersion of risk among different groups (equity issue). We had advised our instructors to emphasize the importance of equity issues and other risk-related qualities. Therefore, the inclination of our sample to assign higher weights to the distribution and circumstances of risk may well be attributable to, or at least be influenced by our information program. But as most reports of the group advisors indicated, the importance of the probability concept was actually appreciated most when the instructor or the contestants during the hearing voiced their support for a broader definition of risk and favored the inclusion of qualitative aspects of risk. In this case, the participants of the planning cells did not perceive the need to compensate for the unidimensional expert opinion and were willing "generously" to assign at least a moderate weight to average losses over time. Hence, we believe that in spite of the tendency to ignore or underestimate the relative importance of probabilities, most participants could be persuaded to consider annual risk figures more carefully, but only if experts or politicians are equally willing to include the public concern for qualitative risk characteristics in their risk analyses or policies.

3. Public information programs on risk will inevitably fail if the objective is to entice people to evaluate risks according to expected values.

Since the difference in experts' and laypersons' understanding of risk is not attributable to the lack of knowledge but to value differences in the interpretation and evaluation of risk-related situations, value changes would be necessary to influence public risk perception. Regardless of how well an information program may be designed, it is unlikely to succeed in altering 
the basic values underlying the public perception of risk.

First, value changes are extremely difficult to induce by information programs (McGuire 1985). Second, the public may well underestimate the value of probabilistic risk analyses for evaluating the seriousness of risk; but with the same degree of legitimacy, one can claim that the expert's understanding of risk underestimates the important circumstances of the risk situation and its institutional handling. Hence, both sides operate under a limited perspective (English 1987). Third, having good arguments available to confirm their viewpoint, most people do not have any incentive to change their value structure and adopt a new concept of risk evaluation.

Finally, there is always sufficient anecdotal evidence to substantiate one's own judgment, whereas direct proof for the expert's concept is difficult to present because risk-related events are obviously stochastic and therefore predictable only on the basis of large numbers of events. Catastrophic events are rare, however, and the hypothetical assessment of failure probabilities (through fault-tree analysis, for example) does not provide any forecast for the performance of an individual plant. TMI or Chernobyl neither prove nor disprove the probability estimates of risk analyses, because single events may occur any time even for low-probability events. Thus it may even be politically reasonable in managing risk to substitute probability estimates with social or institutional ability to control hazardous technologies (as public perception would suggest).

4. Communication that is focused on exchanging information on perspectives and underlying value structures, without claiming superiority for one position or the other, appears to be very effective in enhancing mutual understanding, discussing advantages and pitfalls of different concepts of risks, and facilitating compromises in risk-related conflicts.

This approach implies that each side recognizes and tolerates different perspectives of risk and perceives risk communication as a mutual learning process among experts, policy makers, and citizens. The planning cell experiences demonstrate that most people are able and willing to contemplate other perspectives of risk as long as their own perspectives are respected. Conflicts that seem irreconcilable may indeed be reconciled in an open public discourse if all participants agree that risk is a multidimensional concept that includes different perspectives and interpretations, including scientific as well as public concerns.

The effect of risk communication on attitude formation and change

In addition to the question of how risks were actually perceived by the 
participants of the planning cells and what kind of information was accepted and processed, we were also interested in attitude formation. All our respondents had been asked to select one of the four energy scenarios and to justify their selection. What arguments were reproduced or even originated to back up individual decisions, and how did risk-related information influence this process?

Almost all participants assigned rather high weights to health and safety and to environmental quality. Energy systems perceived as detrimental to health or environment received negative, or at least ambivalent evaluations, even if the economic benefits earned high ratings. The relative importance of the two risk impact factors became even more prominent when respondents were divided into three major subgroups:

1. Materialists (persons who assign highest values to economic benefits and prosperity);

2. Post-materialists (persons who assign highest value to environmental quality);

3. Persons with mixed orientation (Inglehart 1977).

The materialists in our sample ranked environmental quality almost as high as their favored economic performance standards (cf. Table 19.4). Thus, they faced a true value conflict between the two subsets of values. In contrast to them, the post-materialists assigned extremely high weights to environmental quality and only marginal values to economic performance (with the exception of "assuring employment"), in particular costs. Both extreme groups were willing to make trade-offs, but the materialists, probably frustrated by the ongoing positive amplification of environmental quality as a highly appreciat-

Table 19.4. Mean values of different subgroups for rating the importance of value judgments.

\begin{tabular}{lccl}
\hline Value dimension & $\begin{array}{l}\text { Materialist } \\
\text { group }\end{array}$ & $\begin{array}{l}\text { Post-materialist } \\
\text { group }\end{array}$ & $\begin{array}{l}\text { Mixed value } \\
\text { group }\end{array}$ \\
\hline Financial \& material requirements & 15 & 8 & 12 \\
Security of supply & 17 & 10 & 15 \\
Effects on national economy & 15 & 12 & 15 \\
Social impacts & 8 & 7 & 10 \\
Environmental impacts & 13 & 20 & 18 \\
Health/safety & 20 & 25 & 22 \\
Political impacts & 5 & 8 & 3 \\
International consequences & 7 & 10 & 5 \\
\hline
\end{tabular}

-Respondents were asked to assign numerical weights to each of the eight dimensions. The sum of the weights amount to 100 . 
ed social value (social desirability concept), were more inclined to trade off their prior values than the post-materialists who were well aware of the public support for their concerns. Hence they were less willing to sacrifice their environmental concern for an increase of economic benefits. Furthermore, most post-materialists were convinced that, in the long run, environmentally innocuous energy systems would also prove more cost-effective, whereas the materialists acknowledged a strong value conflict between environment and economics. The intermediate group assigned higher values to environmental concerns than to economic ones, but was rather flexible and more relaxed in making trade-offs. But every person in our sample assigned higher or equal weight to health safety than to any of the economic categories.

Probabilistic risk analysis enjoyed little use in backing up or challenging participants' viewpoints or arguments. Conceding that nuclear energy is risky and hazardous, proponents defended their positive attitude by referring to the economic benefits of this energy source that would outweigh its negative impact on health and environment. Only 15 out of almost 500 participants mentioned that the probability of a severe accident was very small and that the risk therefore was acceptable. Apparently, risk analyses were not used as an argument to back up a pronuclear position.

As mentioned above, the economic variables were awarded less importance than health, safety, and environmental quality during the formal procedure of assigning weights to each category. Consequently, the calculated preference (sum of weighted attributes) implied a larger proportion of negative attitudes towards nuclear power than revealed by direct questioning or content analysis of narrative justifications of one's own judgment (Renn et al. 1984). The discrepancy between the calculated preference (strongly antinuclear) and the verbally expressed preference (more in favor of nuclear energy) could be partly explained by the social desirability effect (many people felt social pressure to assign higher weights to socially desirable and "altruistic" goals such as environmental quality and less weight to "egoistic" and more materialistic goals such as cost-effectiveness although they personally found the latter more important), partly by referring to peer group judgments (political parties, unions, scientists, etc.) which were believed to have more competence in evaluating the need and acceptability of nuclear power.

The opponents of nuclear energy needed no probabilities on which to base their arguments. They believed that nuclear energy was uneconomical in the first place so that a balancing between risk and benefit would be superfluous (due to the lack of benefits). The group of undecided persons regarded both, the risks and the benefits to be high, but had difficulties in mentally assigning the trade-offs between the two. They favored a policy in which all other energy sources should be used as much as technically and economically feasible. 
Nuclear energy should be restricted to meeting the residual demand. A group stating that the risk is negligible or small was essentially missing.

The limits of communication were even more visible in two other areas. During our expert survey on assessing impacts of different energy systems, professional proponents and opponents of nuclear energy and solar energy agreed that solar energy is more labor-intensive and thus probably more expensive, however beneficial to employment, and that radiation escaping from a nuclear power station in normal operation would not lead to detrimental environmental consequences.

This information was passed on to the participants in oral and written form. Despite the unanimous support of these two statements by the adversarial science camps, most participants rejected them, apparently because they contradicted central elements of their attitudes. Research on attitude change has long established the finding that even overwhelming evidence by reference groups are not sufficient to change salient components of a person's belief structure (McGuire 1985; Chaiken and Stangor 1987).

The proponents of nuclear energy refused to believe that solar energy might increase direct employment in the energy sector. Opponents remained steadfast in their beliefs that nuclear power plants have a devastating effect on the environment. In both instances, the underlying pattern of attitudes would have been scattered if the information were adopted. Already admitting that nuclear energy is hazardous, the proponents could hardly concede that any economic benefit is linked with solar energy, thus challenging the economic superiority of nuclear energy. The antinuclear group, strongly motivated by its environmental concern, was unable to link any environmental advantage with nuclear energy. Regardless of whether the experts' statements were indeed right or not, this example illustrates a mechanism that social psychologists have denoted as avoidance of cognitive dissonance (Festinger 1957). If a central element of an important attitude is challenged by incoming devious information, the most likely escape is either to reject the information or regard the source of this information as biased or misinformed. This way one may sustain the existing attitude and avoid the painful process of redirecting the belief system.

Yet it would leave a totally wrong impression to infer that during the four days of planning cell procedure, changes in attitudes or beliefs did not occur. Most respondents indicated that they corrected many false assumptions about energy systems and even changed parts of their belief system. Such changes, however, were reported only for energy systems or sources with low emotional involvement. The more unstructured attitudes were articulated and the less they were linked with basic values and commitments, the more often they were changed in the course of the planning cell. Highly politicized energy options, 
such as nuclear energy or conservation, triggered a strong attitudinal commitment that seemed almost impossible to overcome or alter. The presented information in these cases served as a supermarket for selecting good arguments to rationalize prior commitments. Since arguments for both sides were presented, every participant was able to select the information that he or she wanted to hear. Information on less debated energy systems (such as coal gasification or fusion), however, was readily adopted, openly discussed, and incorporated into the existing value framework for energy policies.

In essence, risk information was effective in laying the ground for a rational and well-balanced attitude towards a risk source not yet associated with strong personal value patterns and belief systems. Risk communication efforts are, therefore, most effective early on, before people have committed themselves to one position or another. If that commitment has become fixed, new information is not likely to change it. Rather information is used to collect new arguments and to back up one's own position; contradicting evidence is usually rejected. Either personal experience or a combination of powerful evidence and changes of reference group judgments are necessary to reverse stronglyheld attitudinal commitments.

\section{Experiences with the New Jersey project}

In 1988, the Department of Environmental Protection of New Jersey decided to fund a research project to apply the methods of planning cells to an U.S. audience. The objective of this study has been to elicit regulatory options for land application of sludge. In November 1988, two planning cells were conducted. The process conveyed additional insights into the communication problems and opportunities in the context of a different subject and a different political culture.

Drawing upon our West German education program, we designed the American process in a similar way. We conducted an expert workshop on the risks and regulations of land application of sludge and videotaped all controversial statements. These statements, together with written information material and lectures, were presented to the audience. In addition, we handed out the numerical results of the expert workshop summarizing the experts' judgments on the seriousness of risks and the appropriateness of existing regulations.

Although probabilistic information was part of the education package, it played a less important role than in the West German energy study. The focus of our informational material was on the regulatory provisions and their effectiveness. We also faced hardly any controversy among the experts about 
the seriousness of the risks. With the exception of the risks of organic toxins, all experts expressed rather similar assessments of the risks and felt that health effects were negligible provided that all the regulations were met.

When we implemented the information program with the participants of the two planning cells, we were confronted with two major difficulties. First, the participants were outraged about the task of designing and evaluating regulation since they were fundamentally opposed to having land application of sludge in their neighborhood at all. Second, the participants complained about the selection procedure and were only willing to cooperate if all the abutters to the proposed land application site were invited to participate. Such a request transformed the planning cell into a direct citizen stakeholder group. After two days of difficult negotiations, the participants decided to run the planning cells by themselves and to inform the New Jersey Department of Environmental Protection about their preferences. On January 15, 1989, they sent a report to the Department stating that they were fundamentally opposed to the plan of land application and that they were willing to fight should the Department try to implement its plans.

In spite of the unexpected change of the agenda and the structure of the planning cells, our information package seemed to have had an impact on the participants since some of the problems mentioned in their final document reflected paragraphs from the information material. The citizens also requested to have the videotapes available for their sessions. During the two days of discussion, the participants took advantage of all the prepared lectures and engaged in lengthy discussions with the presenters. They refused, however, to work on the task of evaluating regulations since that was obviously not in their interest. It was clear that our information served primarily as a means to rationalize and justify the decision to reject the land application project, but at the same time it helped to correct unreasonable fears and to focus on issues that posed real concerns.

The most important result in terms of risk communication was the fact that, through the process of elicitation and discussion, the concerns of the citizens became clearer to us and to the funding agency. Our expectation was that citizen would be most worried about potential health effects and odor problems. Although both aspects were raised as concerns during the initial discussions, the emphasis of the citizens was on the transformation of farmland to an industrial "waste dump" (regardless of the risks involved) and the long term effect of sludge application on the quality of the soil. To imagine that, due to cumulative concentration of heavy metals, farmland might be unsuited for further agricultural purposes after 30-40 years of sludge application was most scaring for the farmers in the planning cells. Finally new residents of the area were concerned about economic and social impacts ranging from the elevated 
noise level because of truck traffic to the expected decline of property values. All three clusters of concerns are hardly addressed in the present New Jersey regulations. Thus the two-way communication process helped to gain a better insight of the citizens' concerns and to provide a better platform to match these concerns with new, improved regulation or planning.

\section{Conclusions}

This chapter has described the process of risk communication in planning cells conducted in West Germany in the years 1982-1984. In addition, we presented some more recent insights from a planning cell project in New Jersey. We analyzed the factors that proved to have influenced the effectiveness and failures of our communication efforts. It should be kept in mind that all our insights in risk communication are based only partly on statistical evidence; they were also derived from subjective judgment as an observer of the planning cell procedures. In addition, our communication program was designed for a highly artificial situation. Randomly selected citizens were given paid leave from their workday obligations to evaluate national energy policies. Yet, the intensive interaction between researcher and research subjects, the opportunity to reach a subgroup of the population usually not included in other forms of participation, and the direct access to measuring the success or failure of our information program created a unique and rewarding research experience that yielded valuable results difficult to obtain otherwise. Furthermore, our respondents were highly motivated to meet their role requirements as "value consultants" and to respond to our questions honestly and with a high sense of responsibility not likely to be found in normal survey conditions.

The outstanding result was that risk communication efforts aimed at altering existing attitudes or strong emotional commitments are bound to fail. This may not be surprising for researchers in the field of attitude change, but astounded most of the experts and politicians involved in our West German energy study. Risk sources that have undergone political polarization and extensive public debate have been socially transformed into carriers of symbolic beliefs. These beliefs are not related to the instrumental properties of risk sources. All information relating to the instrumental advantages, disadvantages, and risks may be acknowledged, but will not trigger any attitude change because they do not affect the more powerful symbolic beliefs. In order to influence the symbolic belief systems, either value changes must occur or the issue must be disconnected from the previous symbols to which it has been associated. Both pathways of attitude change are unlikely to be affected by information programs. Direct visual evidence, events that cannot be over- 
looked, steady changes in social value structures, and even forgetting over the course of time are some of the social mechanisms to assure that changes in symbolic belief patterns take place (Meinefeldt 1979). The deliberate change of these patterns through official communication efforts will probably remain illusory.

The principal objective of risk communication should therefore not be to influence or alter people's attitudes towards risk sources, but to provide easily comprehensible tools to laypersons that enable them to understand information about risks, to process probabilistic information, and to evaluate the likely impacts for oneself and society. This goal suggests that the public perception of risk, at least the underlying concerns governing this perception, be adopted as another legitimate perspective for risk management. Scientific concepts of risk are not a priori superior to nonprofessional concepts. This does not mean that scientific estimates of probabilities and magnitudes of risk are only as accurate as laypersons' best guesses. On the contrary, most laypersons would not even tolerate a risk management strategy that relies not on the best available technical estimates but only on public perceptions. The legitimacy of public perception points to dimensions that need to be included when measuring and evaluating risk. The specific circumstances of the risk-related situation, equity issues, catastrophic potential, and other qualitative aspects of risk deserve the same attention as the calculation of numerical probabilities and consequences. Thus risk communication must incorporate a broad conception of risk, and operate with the realization that communication is a two-way process in which both sides should learn from each other.

The planning cell experience demonstrated the possibility of conveying the risk concept as well as the analytical techniques of risk assessment to a layperson audience. Given enough time and practice, nearly everyone in our 24 planning cells was able to become familiar with the probability concept and to contemplate trade-offs even in such sensitive areas as health versus costs. The process accomplished a basic understanding of the problems and choices of risk management, and thus laid the foundation for gaining trust and credibility. Although many respondents did not agree with the actual decisions regulators made in the past, they understood the basic rationale and accepted the agency's way of thinking, without necessarily endorsing or even approving of it. In particular, popular prejudices about hidden motives of politicians or the alleged insensitivity of industry towards pollution could be replaced with a critical, but conscious awareness of the value conflicts and problems a politician, an administrator, or industrial manager faces when making risk-related decisions.

Effective strategies to design communication programs for conveying different risk concepts and enhancing understanding of the actors involved in risk 
management are certainly not easy to develop, but they are available. On the basis of our limited experiences with planning cells, successful communication programs appear to require three essential conditions:

1. Communication strategies should be carefully structured and prepared. Factual information, interpretation of facts, opinions about expected outcomes, and evaluations of these outcomes should be treated separately and communicated in a different format.

Factual information should be collected and verified by experts with different attitudes. Facts can be reported to a lay audience by written or oral presentations. Interpretation of these facts should be presented in a plural form to reveal to the respondents that data can be interpreted differently without being unscientific or biased (Lynn 1986). Videotapes of expert statements or a collection of adversarial essays are valid tools to convey interpretations. The role of values in making risk-related judgments should be clarified. The respondents need the assurance that their values are as legitimate as those of any scientific community. Hearings with experts and risk managers may be effective means to clarify value judgments.

The implications of the risk for the individual and society should be framed in an easily comprehensible yet honest manner. Underestimating the potential ability to understand the risk concept is just as detrimental to the communication process as overtaxing individuals with a scientific jargon that is unfamiliar to most people. The role of experts in communication has to be defined and structured in advance. Expert presentations should be kept brief and professional vanity should be avoided. Videotaping expert statements in controversial questions proved very successful in our communication contexts.

2. Communication strategies should be organized in a dialogue forum. The audience must have the opportunity to voice its concerns to the communicators, to participate in setting the agenda, and to convey its perspective to the policy maker.

Public involvement is not only a premise for reaching the public and gaining their attention, it is also a functional prerequisite for rational policy making. The perspective of the public helps to improve policies and decisions as the policy maker is more aware of the concerns and needs of the affected population. Therefore policy makers should be part of the communication strategy. They should express their willingness to learn from public concern and consider possibilities of using public input in the decision-making process. If policy makers are not willing to learn from the public, the public will probably refuse to learn from them as well.

3. Comprehending risk assessment and risk management provides an apprecia- 
tion of the tasks and problems of regulators and risk managers. Such appreciation is the first step in creating or sustaining trust.

If policy makers are able to demonstrate the openness of the decision making process for incorporating public concern and to guarantee fairness and competence of the key actors in the decision process, trust may prevail even if the respondents do not agree with the trade-offs the decision maker has assigned to the conflicting attributes.

The process of communicating risk is certainly not easy, but our experiences in organizing and conducting planning cells assure us that important risk assessment and management strategies can be effectively communicated. Effective communication does not mean luring people into accepting risks that they fear or wish to avoid. Effective communication means preparing people to understand and to participate actively in debates about risk or risk sources. The major goals are to enhance understanding, to develop mutual respect for the key actors, and to acknowledge the conflicting values in decision making under uncertainty. Ultimately, risk communication should provide a platform for rational conflict resolution and democratic policy making.

\section{Acknowledgment}

The research described in this chapter was funded by a grant from the West German Ministry for Science and Technology and by a grant from the New Jersey Department of Environmental Protection. I would like to thank Dr. B. Johnson from the NJ-Department of Environmentaal Protection for his helpful comments and Jeanne Kasperson for a thorough review of an earlier draft of this paper.

\section{References}

Chaiken, S. and Stangor, C. 1987. Attitudes and attitude change. Annual Review of Psychology 38: $575-630$.

Covello, V.T., P. Slovic and D. von Winterfeldt. 1986. Risk communication: a review of the literature. Risk Abstracts 3, No. 4 (October): 172-182.

Dienel, P.C. 1978. Die Planungszelle. Opladen, West-Germany: Westdeutscher Verlag.

Dienel, P.C. 1980. New options for participatory democracy. Werkstattpapier No.1 of the University of Wuppertal. Wuppertal, West-Germany: University of Wuppertal.

Douglas, M. and A. Wildavsky. 1982. Risk and culture. Berkeley, CA: University of California Press.

English, M.R. 1987. Toward a taxonomy of technological risks. Paper presented at the Conference of New Technologies: Responding to Future Risks. Worcester, MA, May 28-29. 
Festinger, L. 1957. A theory of cognitive dissonance. Stanford, CA: Stanford University Press.

Fischhoff, B.,P. Slovic, S. Lichtenstein, S. Read and B. Combs. 1978. How safe is safe enough? A psychometric study of attitudes toward technological risks and benefits. Policy Sciences 9: 127-152.

Fischhoff, B., O. Svenson and P. Slovic. 1986. Active response to environmental hazards: Perceptions and decision making,. In: D. Stokols and I. Altman (eds), Handbook of environmental psychology. New York: Wiley and Sons, Vol. 2, pp. 1030-1133.

Inglehart, R. 1977. The silent revolution. Changing values and political systems among western publics. Princeton: Princeton University Press.

Kasperson, R.E. 1986. Six propositions for public participation and their relevance for risk communication. Risk Analysis 6, No. 3: 275-281.

Keeney, R. 1980. Equity and public risk. Operations Research 28: 527-534.

Keeney, R., O. Renn and D. von Winterfeldt. 1987. Structuring West Germany's energy objectives. Energy Policy 15, No.4 (August): 352-362.

Lynn, F.M. 1986. The interplay of science and values in assessing and regulating environmental risks. Science, Technology and Human Values 11 (Issue 2): 40-50.

McGuire, W.J. 1985. Attitudes and attitude change. In: G. Lindzey and E. Aronson (eds), Handbook of social psychology. Reading, MA: Addison-Wesley Publications.

Meinefeldt, W. 1977. Einstellung und soziales Handeln. Reinbeck, West-Germany: Rowohit.

Renn, O. 1983. Technology, risk und public perception. Angewandie Systemanalysel Applied Systems Analysis 4, No. 2: 50-65.

Renn, O. 1985. Risk analysis - prospects and limitations. In: H. Otway and M. Peltu (eds), Regulating industrial risk. London, GB: Butterworth.

Renn, O. 1986. Decision analytic tools for resolving uncertainty in the energy debate. Nuclear Engineering and Design 93, Nos. 2\&3: 167-180.

Renn, O., H.U. Stegelmann, G. Albrecht, U. Kotte and H.P. Peters. 1985. An empirical investigation of citizens' preferences among four energy scenarios. Technological Forecasting and Social Change 26, No. 1: 11-46.

Renn, O., G. Albrecht, U. Kotte, H.P. Peters and H.U. Stegelmann. 1985. Sozialverträgliche Energiepolitik. Ein Gutachten für die Bundesregierung. Munich: HTV Edition "Technik und Sozialer Wandel".

The Royal Society. 1983. Risk assessment. A study group report. London: The Royal Society. Ruckelshaus, W. 1982. Science, risk, and public policy. Science 221: 1026-1028. 